\title{
The Impact of Green Energy-saving Construction of Architectural Engineering on the Human Settlement Environment of Traditional Villages
}

\section{Ersilin Wu}

QianDongNan National Polytechnic, Kaili 556000, Guizhou, China Email: 759204731@qq.com

\begin{abstract}
The human settlement environment is the basic and necessary condition for realizing development. At present, there are still a certain number of traditional villages in many areas. Improving the rural human settlements environment plays a particularly important role in ensuring regional development. The improvement of the living environment of traditional villages should be based on the green and energy-saving construction of construction projects to improve the living conditions of the population, ensure the functionality and quantity of public facilities, and raise environmental sanitation standards. These contents are also key factors for building a well-off society and an urgent need for the village population to improve the quality of life.
\end{abstract}

Keywords: construction, green energy-saving, construction method, traditional village, human settlement environment

The improvement of human settlements is the basis for the development of traditional villages. We must adhere to the principles of environmental protection, work to improve the life and production ecology, and be guided by the construction of beautiful and livable, analyze the constraints that affect the sustainable development of the village, and conduct indepth research on specific measures to ensure that environmental governance can be improved. Green and energy-saving construction of construction projects can create a more comfortable living environment, improve the development quality of traditional villages, and create environmental conditions for sustainable and healthy development.

\section{Key points of improving the settlement environment of the village}

Dausadias proposed the definition of "village" in his book. A village is a living environment that can provide people with food, clothing, shelter, and transportation; a village is not just a settlement, it also contains the materials needed by human beings, the natural environment, and human activities, which constitute society. The village is an overall environment. The well-known Chinese scholar Wu Liangyong pointed out in his work "Introduction to Human Settlement Environment" that villages have formed due to the evolution of society. "Because humans have gathered here for a long time and live here, it is closely related to human life. The village is a landmark space, and humans can use nature and transform nature in the village." He believes that the village is not just a certain form. Both market towns and cities can be used as villages. His expression of the village is different from the concept proposed by Dausadias. The basic theory of human settlement environment proposed by Wu Liangyong is based on my country's national conditions. The settlement methods are all around human beings, and they all regard the human settlement environment as a whole. Its components are human beings and the environment, including the materials and housing needed for human life as well as various infrastructures, as well as the living environment. It is an overall living circle and the environment on which humans live ${ }^{[1]}$. There are two levels of the human settlement environment. One is a multi-level biosphere, which includes not only humans, but also the materials and culture required for human behavior and activities; the other is the human settlement itself, which simply refers to the living environment of human beings. The above-mentioned theories are equally applicable to both cities and villages, providing a theoretical basis for the construction of rural human settlements.

Based on the theory of Dausadias' village studies, Mr. Wu Liangyong combined with my country's actual conditions to create the "Science of Human Settlement" and clarified the structure and system of the science of human settlements. He pointed out that human beings are the starting point and end point of human settlement science. Nature is serving mankind, and mankind's food, clothing, housing and transportation are inseparable from nature, and the two rely on each other. The consideration of nature and human beings is the key to achieving sustainable development ${ }^{[2]}$. The human settlement environment plays a transitional role between human beings and the natural environment. The harmonious existence of mankind and nature is the most ideal state, which is that man is an integral part of nature. 


\section{The necessity of implementing green energy-saving construction in traditional villages}

\subsection{Serious waste of land resources, and lack of planning in residential areas}

The chaos of village construction can be summarized in two points. The first point is the lack of reasonable conditions for the construction of public infrastructure. In many rural residential areas, there are many winding roads and few straight roads, and the roads are relatively narrow, so many small agricultural equipment cannot pass. This has caused many inconveniences to the residents' labor and daily life. Another point is to build houses indiscriminately. The houses built are of different orientations, and the styles of the houses are also varied, the decoration styles and standards are not unified, and the building materials are also different, so the overall view is very confusing. The chaotic appearance of residential areas is more due to the lack of scientific and formal planning and design. Many rural homesteads have not been planned and approved by professional departments. The house is built completely according to a basic sketch or even according to the personal preferences and wishes of the residents. The houses built in this way are not only inferior in quality, but poor in use, and the most serious can cause unnecessary casualties and property losses. Although there is a general plan for rural house construction, it is still done by imitating the form of the city. Unreasonable adjustments are made in accordance with changes in the city, making rural land use planning unreasonable and unsustainable. In recent years, with the rapid development of housing construction, the living conditions of rural residents have also changed a lot. The original thatched house was transformed into a masonry house, and finally it was transformed into a building. Three changes to the house were completed in a single generation. The problem that has arisen is that the management and planning of housing construction have not been able to keep up with the pace efficiently. This also makes rural construction chaotic and chaotic. However, modern reductionism believes that the system is a simple superposition of different parts ${ }^{[3]}$.

\subsection{Shortage of various energy and facilities in rural areas}

In many traditional villages, the household energy structure is not scientific enough, and a lot of energy is wasted in vain. In the usual fire and cooking, relying on the burning of wood, straw, and weeds not only increases energy waste, but also releases a lot of smoke, dust, and gas, which destroys the surrounding environment. Energy construction has stagnated, and there is a lack of new energy use and promotion. The energy framework is unscientific, and only a few households will use new energy sources such as solar energy, biogas, and biomass. The construction of the biogas project is only at the initial stage, and the villagers still rely more on the burning of coal and wood. The rural energy framework for production and living needs to be changed as soon as possible. The basic construction and service facilities of traditional village human settlement environment are not sound enough, and there is no supporting policy for rural public construction. Therefore, the quality of life of the villagers is low, and the living environment is constantly being destroyed.

\subsection{Serious environmental pollution, and lack of necessary institutional constraints}

The destruction of the village environment is getting more and more serious, which can be broadly summarized as life pollution, production pollution and industrial pollution. The average pollution trend in the rural areas of Jilin City has increased, and the scope has continued to expand. Because the villagers do not have the concept of environmental protection and the construction of sewage discharge and garbage disposal in the village is not perfect, the production and life of the villagers are affected, and the living environment is destroyed. According to the data on the joint action conference call for centralized environmental improvement in rural areas, nearly 7 million tons of domestic garbage are not treated in rural areas every year, and more than 500 million tons of domestic sewage are discharged everywhere. From the perspective of production pollution, because there is no scientific training, the use of pesticides and fertilizers is far above the standard limit required by the country. Residual pesticides in pesticide containers and excessive use of chemical fertilizers will cause great damage to soil and water. Moreover, the use of agricultural plastic film and diesel fuel will also pollute the environment ${ }^{[4]}$.

\section{Principles of green energy-saving construction in traditional villages}

\subsection{The human-centered principle}

The relationship between human beings, housing and the environment is very close. Human beings are very important. If there are no human beings, the human settlement environment cannot be established. Therefore, the quality of the living environment determines the quality of human living conditions. This must be taken into consideration when constructing a human settlement environment, which reflects the subjective needs of human beings for living conditions and environment ${ }^{[5]}$. 


\subsection{The principle of having practical significance}

The construction of the human settlement environment must meet the needs of mankind, and it must also be combined with the geographical location. No matter how the construction is done, the sustainable development strategy must be considered. Only in this way can our country's economy develop steadily. Therefore, the construction of the human settlement environment should be determined according to the person and geographical location, so that the construction of the human settlement environment can be implemented, and it has practical significance.

\subsection{The principle of combining dynamics and stability}

The selected elements must be stable and not change too quickly. In addition, with the development of the times, the human settlement environment has also changed. The elements selected for the construction of rural human settlements must be able to adjust with the development of the times

\section{How green energy-saving construction of architectural engineering affects the living environment of traditional villages}

\subsection{The improvement of the human settlement environment should be planned as a whole}

Due to the extensive content involved in the improvement of human settlements, the green and energy-saving construction of construction projects needs to be considered from a systematic perspective. Systemic needs to act on different levels and specific tasks. In order to comply with the overall planning rules, it is recommended to proceed from the following points. First, we must carefully arrange the entire village as a whole to realize the simultaneous advancement of various affairs in the region. For projects that are difficult to advance simultaneously, it is necessary to give priority to developing villages with more mature conditions based on conditions. The preparatory work should be sufficient, and the progress should be carried out in an orderly manner. You can experiment with a batch first, and then promote it after gaining experience. Second, the green and energy-saving construction of construction projects should make overall plans for the overall requirements for improving the living environment and factors such as economy, environment, and culture. While vigorously developing the economy, we must also take care of other tasks. The human settlement environment must include the entire region and multiple levels, and there must be no omissions, no over-enhancement of a certain content, and no problem holding back. In the formulation of the plan, it is necessary to highlight the relevance of the levels, and not to selectively implement some policies in a differentiated manner, and to ensure the integrity and rationality of the plan ${ }^{[6]}$.

The ultimate goal of improving the living environment is to realize the overall revitalization and development of rural areas. There are still more than 30 years away from the set goal. Due to the long time, planning must be based on objective laws, strengthen scientificity, and ensure foresight. For example, in terms of urban development, the increase in urbanization rate will lead to the disappearance of some villages. Therefore, small towns must study the problem of future population growth in advance, plan supporting infrastructure in advance, arrange facilities rationally, and improve their functions. In construction planning, it is necessary to form characteristics and have a plan. In order to achieve stable development of agriculture, in addition to adopting advanced green energy-saving technologies, special attention must be paid to the protection of human settlements. The living environment needs to do the supporting work ahead of time, and measures to prevent environmental pollution must be taken. This is the most important content of environmental pollution prevention and control.

\subsection{Promote the protection of the ecological environment}

The construction of ecological livability is conducive to changing the original dilapidated face of the countryside. It is suggested that we should seize the development opportunities of beautiful villages, give full play to the advantages of green and energy-saving construction, and achieve continuous changes in the appearance and appearance of the village. It is also necessary to combine the improvement of human settlements, continuously improve production and living conditions, and create a new ecological and livable environment. Introduce a market-based cleaning development model to improve management and hygiene capabilities. Important infrastructure such as road traffic, water supply, power supply, and communication network should be regarded as key development projects to improve the development environment and human settlement environment. To ensure the scientific development of agricultural resources, we must strengthen the concept of sustainability in development. To ensure the sustainability of development, in addition to realizing reasonable input of human, material and financial resources, it is also necessary to change the original development thinking. The development of agricultural resources must not only ensure the use of contemporary people, but also consider future development to realize the rational use of resources. The sustainable development of agricultural resources must be based 
on the protective development of agricultural resources.

\section{Conclusion}

The construction of the human settlement environment in traditional villages is the focus of the construction of a new socialist countryside in my country. How to ensure the improvement of the rural human settlement environment, improve the living standards of farmers, and improve the quality of development in rural areas are the key and outstanding problems to be solved in the current green and energy-saving construction of construction projects, and it is also the top priority of promoting the sustainable development of rural economy.

\section{Project}

Project name: Theoretical Innovation Project of Guizhou Province (joint project)

Project number: GZLCLH-2021--248

Topic name: Optimization of indoor and outdoor space of human settlements in Tunpu cultural village based on the new urbanization in mountainous areas - Taking Longli as an example

\section{References}

[1] Wu Liangyong. On the human settlement environment. Urban Development Research. 2015; 1(2): 89.

[2] Cao Shimin, Zhang Jiajing, Wang Yingluo. Research on the Renewal of Old Residential Districts Based on the Theory of Sustainable Development: Taking Mingwa Gallery in Nanjing, China as an Example. Architectural Knowledge: Academic Journal. 2014; (B10): 2-3.

[3] Cao Shimin. Research on Nonlinear Design of Residential Buildings: A Case Study Based on Singapore. Theoretical Research on Urban Construction (Electronic Edition). 2014; (34): 1492-1493.

[4] Hu Wei, Feng Changchun, Chen Chun. Research on the Optimization System of Rural Human Settlement Environment. New Countryside Construction. 2016; 6(8): 12.

[5] Zhao Qiuli. (2016) Research on the optimization and construction of rural human settlement environment in Zhejiang Province. Zhejiang University, Hangzhou.

[6] Sun Yuejie, Ye Ping, Wang Yong. Analysis on the improvement of rural human settlement environment in the central area. Jilin Agricultural Sciences. 2018; 36(24): 6. 